\title{
Liberalismo y nacionalismo en Grecia, 1900-1936
}

\author{
Edward Malefakis
}

Es evidente que todas las naciones tienen mucho en ellas que es sui generis, pero Grecia posee más de lo que es habitual. De ello que sea especialmente árduo tratarla en un contexto comparativo. Indudablemente la historia griega exhibe muchas semejanzas con la de otros países del sur de Europa -España, Italia y Portugal- estudiados en este congreso, pero también muestra algunas diferencias fundamentales. Las que siguen son, a mi juicio, las diferencias más importantes que distinguian a Grecia de sus vecinos del Mediterráneo occidental a comienzos del siglo xx:

a) Grecia era una nación-Estado más joven que los restantes países. Pese a que el moderno Estado griego se había constituido oficialmente en 1830, tres decenios antes de la unificación de Italia, era mucho más reciente que el Estado italiano en términos de continuidad. En Grecia, el Estado surgió de un vacío, debido a que, durante casi 400 años, desde que los turcos destruyeran los últimos restos del Imperio Bizantino, no había existido Estado griego alguno de ninguna indole. Por el contrario, pese a no haber un Estado italiano unificado antes de 1860, Italia contaba con una tradición ininterrumpida de estados regionales, algunos de los cuales (como el Piamonte) eran muy fuertes, y otros (como Toscana) muy sofisticados.

b) Grecia era una nación-Estado mucho menos completa que las restantes. El Estado creado en 1830 tan sólo comprendía el $37 \%$ del territorio que constituye la Grecia actual, y una parte aún menor de lo que la mayoría de los griegos consideran como las tierras que en justicia les pertenecian. Nunca se definió con exactitud qué territorios debían constituir la nueva Grecia, pero como mínimo debía incluir aquellas partes del Imperio otomano en que se habían asentado grandes cantidades de griegos. Con la anexión de las Islas Jónicas y de Tesalia, Grecia alcanzó el 49\% de sus dimensiones actuales a fines del siglo xIX; no obstante, la mayoría de los griegos seguían viviendo fuera del Estado griego, en la diáspora. 
Sólo tras los enormes logros territoriales y demográficos conseguidos en las Guerras Balcánicas de 1912-13 residieron en Grecia más de la mitad de todos los griegos.

c) Por el hecho de ser Grecia un Estado nuevo e incompleto, el nacionalismo y el irredentismo fueron las grandes fuerzas impulsoras del siglo XIX y comienzos del XX. Asi fue en particular después que la «Megali Idea" (la "Gran Idea", es decir, una Grecia imperial que remedara al Imperio bizantino, con la capital en Constantinopla y dominios que se extendieran a gran parte de los Balcanes y Anatolia) se estableció como principal ideología oficiosa en la década de 1840. Otra fuente de nacionalismo surgió en los años 1880, cuando Bulgaria comenzó a contender por Macedonia y Tracia, que los griegos consideraban suyas por derecho. Nada hay comparable al irredentismo griego en España o Portugal, que eran ambas naciones-Estado constituidas desde antiguo, y que se consideraban esencialmente completas. En Italia, el irredentismo en torno al Trentino y Venecia-Giulia adquiría importancia política de forma esporádica, pero nunca llegó a predominar en la sensibilidad popular o la política gubernamental tanto como en Grecia.

d) Grecia era mucho más dependiente de las grandes potencias que ninguna otra de las naciones de Europa meridional, incluido Portugal. Las intervenciones militares inglesa, francesa y rusa de los años 1827-30 habían hecho posible la independencia griega; la diplomacia de estas "potencias garantes" había permitido a Grecia la adición de importantes territorios en 1864 (las Islas Jónicas) y 1881 (Tesalia); había contribuido a asegurar la autonomía cretense; y había protegido a Grecia en momentos de crisis, como su derrota en la guerra de 1897 contra el imperio Otomano.

e) Esta dependencia era enormemente costoso psicológicamente para los griegos, y suscitó un profundo resentimiento que no caracterizaba, por ejemplo, la actitud portuguesa hacia Inglaterra, o la búlgara hacia Rusia. Si bien en términos generales la intervención de las grandes potencias había sido predominantemente benéfica para Grecia, también había sido en muchas ocasiones humillante. En la década de 1850, el puerto principal de Grecia fue bloqueado dos veces porque su política entraba en conflicto con las de Inglaterra y Francia. Más tarde Grecia se vio obligada a aceptar un consejo de control internacional que vigilara sus finanzas y garantizara el pago de la indemnización debida a los turcos a causa de la guerra de 1897. Muchos pueblos asiáticos, africanos y latinoamericanos fueron tratados de esta manera por las Grandes Potencias en el siglo XIX, pero ningún otro de los europeos.

f) Si es cierto que su situación internacional era más complicada, socialmente Grecia era menos compleja que sus vecinos del sur de Europa. 
Su economía estaba menos desarrollada, con una mayor proporción de la población y de la renta nacional vinculados a la agricultura, y con índices de urbanización e industrialización más bajos. Existía, claro está, una clase comercial y los griegos se habían adaptado bien a la edad del barco de vapor, por lo que su ancentral tradición marítima seguia siendo vigorosa. Pero en términos generales, la sociedad griega estaba sólo ligeramente diversificada, sin grandes extremos ni de pobreza ni de riqueza.

No se puede hablar apenas de clases consolidadas. Dentro del campesinado, con mucho el grupo más numeroso, la estratificación era relativamente escasa. Debido a que habían sido expulsados los antiguos terratenientes turcos, y entre los años 1830 y 1850 quedaron disponibles para su asentamiento enormes extensiones de tierra nacional, la propiedad estaba muy repartida, existían pocas fincas grandes, y no había una clase de jornaleros rurales sin tierra. Iba formándose lentamente un proletariado urbano, pero antes del siglo xx sus dimensiones no eran suficientes para sostener un movimiento obrero organizado, ni socialista ni anarquista.

Tampoco existía una élite fuertemente consolidada. Cuatro siglos de dominio otomano habían acabado con la clase dirigente autóctona. En cierta medida, habían aparecido sucesores entre los descendientes de los dirigentes regionales de la Guerra de Independencia, pero entre los miembros de las familias fanariotas que se habian fortalecido bajo el Imperio otomano, y -más adelante en el siglo xix -entre los griegos de la diáspora recientemente enriquecidos, ya fueran los que habían prosperado dentro del imperio otomano, ya con el comercio de granos ruso, o con el algodón egipcio. Pero no se trataba de una élite tan sólida y bien articulada como la existente en el resto de la Europa mediterránea.

g) Menos atormentada por divisiones sociales, la política griega estuvo también menos perturbada por conflictos institucionales durante el siglo xIX. Acaso debido a que se habian generado sentimientos más fuertes de identidad de grupo e igualdad a causa de la prolongada dominación turca y a la masiva participación popular en la Guerra de la Independencia, algunas instituciones básicas de la democracia fueron más generalizadamente aceptadas en Grecia que en otros lugares. El sufragio universal masculino se concedió muy pronto (1843) y nunca después fue seriamente cuestionado. A partir de 1864 la legislatura era unicameral, sin cámara alta que pudiera actuar como freno a la baja, de elección popular. La censura no fue sistemática y en las grandes ciudades se desarrolló poco a poco una vigorosa prensa libre. La Iglesia era menos problemática que en Portual, España o Italia, debido en parte a sus fuertes simpatías hacia la lucha de liberación, pero también debido a la tradición ortodoxa (si se compara con la católica) de pasividad política en la mayoría de las cir- 
cunstancias, y a su carácter menos jerárquico. Salvo en dos ocasiones, 1843 y 1862 , el Ejército tampoco fue en Grecia tan activo políticamente como en España o Portugal, pese a que esta situación se alteraría drásticamente a partir de 1900.

h) La corona fue la única institución repetidamente cuestionada, aunque más bien a nivel personal que institucional. La falta de arraigo de los sentimientos monárquicos se debía a lo reciente de su establecimiento y al origen y educación extranjeros de los dos reyes de Grecia del siglo xIx. A causa de su incompetencia y sus tendencias absolutistas, el primer rey, Otto de Baviera, inició la monarquía con paso particularmente desafortunado, y gobernó en una atmósfera de tensión casi continua durante treinta años antes de ser finalmente derrocado en 1862. Jorge de Dinamarca, que vino a continuación, suavizó los conflictos y durante su largo reinado de cincuenta años (1863-1913) llegó incluso a suscitar cierto favor hacia la monarquía. No obstante, gran parte del antiguo malestar existente contra la Corona permanecería latente y estallaría en el nuevo siglo.

i) Con divisiones sociales más débiles y menores disensiones sobre la organización institucional, las tradicionales demarcaciones políticas entre derecha e izquierda no tienen tanto sentido en la política griega como en la del resto de Europa meridional. No se puede hablar tanto de radicales, liberales y coservadores como de facciones políticas sin gran definición ideológica, centradas en torno a alguna personalidad descollante. La principal divisoria era la existente entre los que podrían denominarse modernizadores - que favorecían el aplazamiento de las ambiciones irredentistas hasta que la potencia de Grecia pudiera ser desarrollada mediante una política de austeridad - y populistas, que celebraban los sentimientos nacionalistas y minimizaban la necesidad de impopulares medidas fiscales. Fue ésta una división recurrente, pero cuando quizá queda mejor ejemplificada es en las décadas de 1880 y 1890 por Trikoupis al frente de los modernizadores, y Delivannis de los populistas.

i) El malestar político griego, dado que no se fundamentaba en fuertes divisiones sociales $e$ institucionales y carecía de partidos políticos bien definidos que pudieran canalizarlo, tendia a ser peculiarmente vago y fluido. No significa esto que fuera débil o escaso. Aunque no existían grandes grupos proletarios, ni rurales ni urbanos, el extremado retraso de la economía griega engendraba una pobreza ampliamente difundida, que a su vez generaba resentimiento. Estaba además la frustración que suscitaron los repetidos fracasos de la historia posterior a la independencia, especialmente con respecto a la incapacidad de Grecia para crear una sociedad y un Estado comparables a sus predecesores de la antigüedad y a los bizantinos. Pero la insatisfacción política no estaba tan claramente 
estructurada como en otros países del sur europeo y este hecho, junto a la situación internacional, contribuyó en gran medida a los imprevisibles giros que la historia griega describiría en los cuatro primeros decenios del siglo $x x$.

A comienzos de nuestro siglo Grecia se halló inmersa en una aguda crisis política similar a la que estaban experimentanto España, Portugal e Italia. Su derrota en la guerra de 1897 contra el Imperio otomano había sido sin duda tan humillante como la derrota de España en Cuba en 1898, - la derrota de Italia en Etiopía en 1896. Al igual que en España y Portugal, las principales figuras políticas de los anteriores decenios habían muerto o estaban desacreditadas, dejando al país carente de dirección. La economía griega estaba en peor estado que la de los demás, debido a que no se había recuperado todavía de la caída de precios de su principal producto de exportación, las pasas de Corinto, a comienzos de la década de 1890 , y, tras la guerra de 1897, se vio cargada con el peso adicional de tener que pagar una cuantiosa indemnización a los victoriosos turcos.

Sin embargo, contrariamente a lo que ocurriría en el resto de Europa meridional, la crisis griega de comienzos de siglo no se prolongó hasta la I Guerra Mundial. El dramático giro de los acontecimientos ocurrido en Grecia hizo que el período inmediatamente anterior a la guerra se convirtiera posiblemente en el mejor de toda su historia moderna. No podemos examinar aqui de forma detallada este cambio, pero sus dos rasgos principales fueron la súbita aparición de un líder enérgico capaz de forjar un programa dinámico de cambios internos, y la realización aún más repentina de una parte importante del sueño irredentista de Grecia, tanto tiempo frustrado.

La secuencia de los hechos comienza con el golpe militar liberal de 1909. Este terminó con el status quo político: denunció a los antiguos e ineficaces partidos y la ingerencia del rey en los asuntos políticos y militares, y desembocó en 1910 con la llamada a Atenas de Eleuterios Venizelos. Venizelos se había creado una gran reputación en Creta durante los dos decenios precedentes como dirigente del movimiento que daría la autonomía a la isla bajo la soberanía nominal del Imperio otomano. Con pasmosa rapidez y facilidad, Venizelos se adaptó al gobierno de toda una nación. No solo consiguió granjearse la adhesión popular más generalizada jamás lograda por un político griego, sino que también propugnó un programa de ambiciosas reformas políticas y modernización económica que, además, no quedó en simple propuesta sino que en gran parte fue realmente llevado a la práctica.

Por si fuera poco, dos años después de ascender al poder, Venizelos tuvo la habilidad de saber sacar provecho de las dificultades en que se 
hallaba el Imperio otomano. Aún desorganizado a consecuenicia de la revuelta de los Jóvenes Turcos de 1908, y de la guerra que se había iniciado con Italia en 1911 a causa de Libya, el Estado otomano se vió además amenazado por la alianza entre Serbia y Bulgaria, a la que Venizelos se apresuró a incorporarse. El ataque conjunto de esta nueva agrupación de enemigos en el otoño de 1912 ocasionó el derrumbamiento del ejército turco, y la mayor parte de los territorios turcos, aún considerables, de los Balcanes cayeron ante los aliados. Grecia fue particularmente afortunada en sus victorias, obteniendo Epiro, la mayor parte de Macedonia, Salónica (por entonces la segunda ciudad del Imperio otomano) y muchas islas del Egeo. Además, ahora se permitió a Creta unirse a Grecia. De un solo golpe, tras casi un siglo de desesperanza y derrotas, tanto el territorio como la población de Grecia quedaron casi duplicados.

Pocas veces ha habido una figura política tan triunfante en tan poco tiempo. Para muchos griegos era como si sus sueños se hubieran hecho al fin realidad, y el cielo les hubiera enviado un semidiós para guiarlos hacia cotas aún más excelsas. Así pues, contrariamente a España, Portugal o Italia, el estado de ánimo era jubiloso en Grecia en vísperas de la I Guerra Mundial. Por primera y única vez, una sola persona había conseguido trascender los conflictos recurrentes entre modernizadores y populistas/irredentistas que de forma tan continua han caracterizado la moderna historia de Grecia, desde Marrokordatos y Kolettes a principios del siglo XIX, pasando por Trikoupis y Deliyannis a finales del XIX, hasta Karamanlis y Papandreou a fines del $x \mathrm{x}$.

Pero no todo el mundo entonó el aleluya, claro está. Para los viejos políticos desbancados por el golpe de 1909 y por los éxitos de Venizelos entre 1910 y 1913, la buena estrella del nuevo líder amenazaba con excluirlos definitivamente del poder. También en los círculos de la corte representaba Venizelos un peligro potencial. El golpe militar que le habia llevado al poder tenía ribetes antidinásticos. Pese a que el propio Venizelos creía firmemente en la monarquia constitucional y tan sólo aspiraba a limitar, y no eliminar, el poder real, la magnitud misma de su carisma redujo al rey a una categoría secundaria.

La situación de Grecia no era tampoco tan brillante como pareció a primera vista. La humillante derrota en los Balcanes indujo al gobierno otomano a lanzar una política de turquificación radical en Asia Menor, que tuvo como consecuencia la persecución de la minoría griega y otras minorías que aún residían allí. Bulgaria, aliada en la primera fase de las Guerras Balcánicas, se había convertido en enconada enemiga de Grecia en la segunda fase. Por último, estaba el problema de integrar en el Estado griego los inmensos territorios obtenidos en 1912-13 y a sus po- 
bladores, una tarea especialmente árdua en Macedonia, dadas sus numerosas minorías no griegas.

Incluso bajo las circunstancias rnás favorables, pues, Grecia se habría enfrentado a una serie de graves problemas a partir de 1913. Pero, incuestionablemente, el estallido de la I Guerra Mundial dificultó aún más su trayectoria. En sus primeros meses, la Guerra no presentó especiales conflictos en Grecia, pero una vez que Turquía se hubo unido a las potencias Centrales en octubre de 1914, y sobre todo después que Gran Bretaña y Francia decidieran la expedición de Gallipoli con objeto de abrir el estrecho en febrero de 1915, se multiplicaron las presiones para que Grecia entrara en la guerra. Con toda su ferocidad y sus profundas consecuencias de gran alcance, la famosa lucha intervencionista en Italia, anterior a mayo de 1915, fue superada en intensidad, duración e importancia por su equivalente griega.

Para Venizelos y sus partidarios, ello representó una oportunidad incomparable para repetir los éxitos de las Guerras Balcánicas a mayor escala, y hacer realidad el viejo sueño de dejar los nutridos y ancestrales asentamientos griegos de Asia Menor bajo gobierno griego. Nunca más habría tantas grandes potencias interesadas en la caída del Estado otomano, ni tan dispuestas a premiar a Grecia su contribución a esta empresa. Para el rey Constantino y su círculo el sueño irredentista también era sugerente, pero tras muchas vacilaciones iniciales lo rechazaron por diversos motivos. Entre ellos figuraban la solidaridad ideológica con la parte menos liberal de la guerra; la convicción de que la campaña de Gallipoli estaba condenada al fracaso; la convicción, también, de que las potencias centrales podían ganar la guerra y castigar a Grecia por haber apoyado a la Entente; la creencia de que, aún si ganara la Entente, Grecia no podría conservar permantemente los territorios de Anatolia, puesto que la población griega de estas tierras, siendo considerable, era no obstante claramente minoritaria salvo en pequeñas zonas litorales muy alejadas entre sí.

El conflicto comenzó en marzo de 1915, cuando Constantino, habiendo accedido en un principio a la intervención en favor de la Entente, empezó a manifestarse contrario a ella. Venizelos dimitió y se celebraron elecciones en junio, ganadas por los partidarios de éste por un amplio margen. Sirviéndose de diversas estratagemas, el rey demoró hasta fines de agosto el nuevo nombramiento de Vanizelos como primer ministro. Seis semanas después, la crisis de marzo se repitió con perfiles más extremos. Para los venizelistas, el rey actuaba inconstitucionalmente al prescindir de una figura que tan recientemente había ganado un enorme mandato electoral. Para los monárquicos, era una medida justificada por la continua insis- 
tencia de Venizelos en que Grecia se uniera a la Entente. Una política que les parecía irresponsable en marzo, lo era mucho más en octubre: la campaña de Gallipoli había fracasado, como habian pronosticado los monárquicos; Serbia, la única aliada de la Entente en los Balcanes, estaba al borde del derrumbamiento; las potencias centrales se vieron reforzadas cuando Bulgaria se incorporó a ellas a fines de septiembre. Pese a todo esto, Venizelos había aprobado precipitadamente y sin respetar todos los trámites legales el desembarco de tropas en Salónica el 1 de octubre, con lo cual la segunda ciudad de Grecia quedó a todos los efectos a merced de los deseos de la Entente. ¿Cómo es posible que semejante primer ministro no fuera dimitido, especialmente estando el rey dispuesto a celebrar nuevas elecciones?

Pero las elecciones, aplazadas hasta mediados de diciembre, resultaron en un mandato mucho menos claro que las de junio. Es evidente que el rey no contaba con una gran adhesión, pero era igualmente evidente que el atractivo de Venizelos había disminuido considerablemente en los anteriores seis meses. Aparte del desprecio de la Entente por la soberanía griega al ocupar Salónica, el martirio de Serbia y otros acontecimientos hacían cada día más claro el horror de la guerra. La ambigüedad de los resultados se debía a que las elecciones habían sido indisputadas y sólo había participado un $36 \%$ del electorado. ¿Habían obedecido la mayoría de los votantes la llamada venizelista de abstención, alegando que las elecciones eran ilegales y estaban amañadas? ¿O es que los monárquicos habían mostrado un apoyo no desdeñable logrando que más de un tercio del electorado participara, pese a ser las elecciones indisputadas?

La escisión se profundizó en 1916. Los monárquicos recurrieron a todos los medios para consolidar su situación de poder, especialmente llevando a cabo masivas purgas de venizelitas entre las filas administrativas, militares y policiales. Procuraron también apaciguar a las potencias centrales, que entonces parecian triunfar en los Balcanes, con grandes concesiones, lo cual tuvo tan sólo un efecto contraproducente cuando la Entente bloqueó Atenas primero, y después reforzó los ejércitos de Salónica y lanzó un ataque contra Bulgaria. La derrota de esta ofensiva abrió el camino para la ocupación de la mayor parte de la Macedonia oriental por parte de Bulgaria, sin resistencia alguna del ejército griego de la zona. La división de facto de Grecia quedó institucionalizada en octubre, cuando Venizelos creó un gobierno provisional en Salónica y declaró la guerra a Alemania y Bulgaria. La Entente comenzó entonces a tratar abiertamente al gobierno del rey como enemigo, exigiéndole la entrega de armas, equipamiento y posiciones militares, y obligando al cumplimineto de estas exigencias con un nuevo bloqueo. Poco después incluso desembarcaron 
tropas en Atenas mientras la ciudad era bombardeada por barcos cercanos a la costa, actos que impulsaron a los monárquicos locales a formar turbas de linchamiento para apalear o incluso matar a los venizelistas. Pero Inglaterra y Francia no se habían decidido aún a emplear toda su fuerza contra Constantino, por lo que, durante ocho meses, de octubre de 1916 a junio de 1917, Grecia quedó dividida en dos gobiernos, quedando todo el territorio continental salvo Macedonia bajo dominio monárquico, y la mayoría de las islas junto a Macedonia bajo el régimen venizelista. La unidad nominal fue una vez más restaurada cuando la Entente exigió la abdicación de Constantino, y Venizelos pasó a ser primer ministro el 26 de junio de 1917 en Atenas.

Pero las heridas acumuladas durante los dos años precedentes no eran fácilmente curables. Así como anteriormente se había hostigado y purgado a los venizelistas en la Grecia continental, esta vez le tocó el turno a los monárquicos; las divisiones eran especialmente acusadas en el seno de las fuerzas militares, puesto que había que unir a los dos ejércitos que se habian formado durante los dos años previos. La población no acogió bien la orden de una movilización más amplia y tampoco se produjeron victorias griegas espectaculares que pudieran justificar moralmente la política de Venizelos con mirada retrospectiva. En realidad, Grecia fue la única nación entre todas la europeas en que los aspectos militares de la Guerra Mundial representaron un anticlímax, de menor importancia en su historia que la enconada polémica sobre la posibilidad de intervenir en dicha contienda.

No obstante, el período de postguerra parecía triunfante. Venizelos se convirtió en el hombre mimado de los diplomáticos reunidos en Versalles, y obtuvo increibles concesiones territoriales, entre ellas la Tracia occidental, a expensas de Bulgaria, y la Tracia oriental más la región importantísima de Asia Menor en torno a Esmirna, de Turquía. La «Grecia de los dos continentes y los cinco mares" (el Mar Negro y el Mar de Mármara, así como los mares Egeo, Jónico y Mediterráneo) estaba ya cercana. Pero, para convertir estas concesiones en realidad, hacian falta fuerzas militares, por lo cual Grecia quedó en pie de guerra en su frontera norte y, a partir de mayo de 1919, también en Anatolia. En el verano de 1920 hubo de ser lanzada una primera ofensiva griega para obligar al Sultán a firmar el tratado de paz. Pero su consentimiento fue inútil dado que un movimiento nacionalista turco dirigido por Mustafa Kemal («Ataturk)» se alzó contra él y comenzó a atacar las posiciones griegas próximas a Esmirna. En esta atmósfera se celebraron, en noviembre de 1920, las primeras elecciones en cinco años y, para asombro de los coetáneos, resultaron en la derrota de Venizelos. El electorado rechazó al gran dirigente pese a la magnitud de sus logros, unos por el resentimiento que había suscitado el exponer 
a Grecia a las presiones de la Entente de 1915 a 1917, otros porque estaban cansados de las constantes movilizaciones y guerras.

Así comenzó un nuevo ciclo de reacción cuando Constantino volvió del exilio para sentarse en el trono, y sus adeptos hostigaron y purgaron a los venizelista que habían ocupado la mayoría de los puestos gubernamentales y militares desde 1917. Sólo en un aspecto se prepetuó la política venizelista: olvidando sus anteriores dudas sobre la viabilidad de los territorios griegos en Asia Menor, los monáquicos decidieron retener Esmirna a cualquier precio. Hacia marzo de 1921 esta decisión había producido una segunda y mucho mayor ofensiva militar griega, esta vez desde Esmirna hasta el corazón de Anatolia en un intento de aplastar las fuerzas de Ataturk. La ofensiva casi había alcanzado Ankara en agosto, pero fracasó estrepitosamente en su objetivo estratégico. Los ejércitos turcos no sólo quedaron intactos, sino que sus fuerzas aumentaron constantemente al ir difundiéndose el ardor nacionalista. Un año después, Ataturk estaba preparado para lanzar su propia contraofensiva y los ejércitos griegos, excesivamente desplegados, cayeron ante ella. Pasadas dos semanas, el 9 de septiembre de 1922, habian sido forzados a retroceder unos 650 kilómetros, y hasta el mar cuando Ataturk ocupó Esmirna. Comparada con la escala de esta debacle, la reciente derrota del ejército español en Annual era insignificante.

En Grecia, la derrota de 1922 suele concerse como "la Catástrofe». Y merece este nombre, porque no se había producido un desastre igual en toda la historia moderna griega. Todo el prestigio que Grecia había logrado adquirir en años recientes desapareció. No sólo se perdió la región de Esmirna, sino que además Turguía obligó a Grecia a devolver la Tracia oriental. Mientras tanto, Italia incumplió su promesa de devolver las islas del Dedecaneso, y Bulgaria empezó a disputar su concesión de Tracia occidental. Y lo que es más importante, los casi dos millones de griegos étnicos que seguían viviendo de Anatolia se vieron en peligro salvajemente perseguidos por los victoriosos turcos -especialmente en Esmirna, que fue brutalmente arrasada - pronto serían también expulsados de sus ancestrales tierras. El golpe psicológico fue también grave: durante todo un siglo, el espíritu griego se había visto impregnado por la "Megali idea". Pero se hizo patente que Constantinopla no volvería jamás a ser griega, ni tampoco parte alguna de Asia Menor. ¿Qué aspiraciones podrían definir y sostener en adelante a la nación griega?

Una consecuencia menos evidente del dramático ciclo de acontecimientos ocurrido entre 1912 y 1922 fue que alteró de modo definitivo la estructura de la vida política griega, asemejándola más a la española, la portuguesa o la italiana. Gracias a las anexiones territoriales de 1912-13 
y a la incorporación de Tracia occidental en 1919, Grecia era ahora un país mucho más grande (aproximadamente un $40 \%$ mayor que Portugal), con regiones más claramente definidas y más variadas. Su sociedad se había hecho también más completa. Esto en parte de debía a la creciente importancia del proletariado urbano, especialmente en Salónica, que había sido posiblemente el principal centro fabril del Imperio otomano. Pero la diferencia fundamental fue la afluencia sin precedentes de refugiados, proporcionalmente más numerosa que ninguna de las anteriores o posteriores de toda Europa (los que se quedaron definitivamente en Grecia constituian un $20 \%$ de sus 6,2 millones de habitantes del censo de 1928). Aunque provenían de clases sociales y regiones muy diversas, los refugiados tenían en común sus traumáticas experiencias y un empobrecimiento reciente, con lo cual su presencia tendió a radicalizar la política griega, especialmente en las ciudades, a las que se dirigieron en cantidades desproporcionadas.

Los conflictos institucionales también pasaron a desempeñar un papel más importante en la política griega. Del mismo modo que los griegos se refieren al desastre de 1922 como «la Catástrofe", el ciclo de disensiones entre constantinistas y venizelistas de 1915-22 se conoce como "el Cisma". El país había estado tan profundamente polarizado que, a raíz de aquel momento, la monarquía fue una cuestión permanentemente debatida, glorificada por unos como garantes de orden y prosperidad, detestada por otros por ser la causa primera del atraso griego. También el ejército se habia politizado profundamente. Durante el siglo xIX careció de un sentido de identidad corporativo fuerte, y se abstuvo de intervenir en política de modo tan sistemático como fueron las intervenciones de los ejércitos español y portugués. Con el golpe de 1909 empezó a operarse el cambio, pero la gran transformación se produjo durante los años del Cisma, cuando los oficiales fueron destituidos o ascendidos según fueran sus lealtades políticas, y cuando dos ejércitos distintos, uno conservador y otro liberal, se perfilaron embriónicamente entre los adeptos a Constantino y a Venizelos. Sólo la Iglesia quedó relativamente incuestionada porque, dado el carácter no jerárquico de la iglesia ortodoxa, los excesos políticos del clero (como fue la excomunión de Venizelos por parte del Arzobispo de Atenas en 1916 por «traición al rey y a la patria») tendían a considerarse puramente representativos de personas o facciones determinadas, no de toda la institución en general.

En virtud de estas decisivas transformaciones, se hace más comprensible al lector español la historia griega del periodo de entreguerras, pese a que las estructuras sociales siguieron siendo menos claras y el malestar político más difuso que en el resto de la Europa mediterránea. Para mejor entenderlo, el período de entreguerras puede dividirse en cuatro grandes 
fases: a) una agitada de 1922 a 1927, en que fue abolida la monarquía y proclamada una república, aunque el nuevo régimen se mostró en exceso inestable y no consiguió arraigar bien; b) un período estable de 1928 a 1932, en que la república, presidida por Venizelos, pareció consolidarse; c) una vuelta a la turbulencia política de 1933 a 1936, en que los conflictos partidistas destruyeron la república y fue restaurada la monarquía; d) el establecimiento, con apoyo del rey, de la dictadura de Metaxas, de 1936 a 1940 .

Veamos la primera fase. El caos reinó en Grecia durante los meses finales de 1922. Dos semanas después de la caída de Esmirna, oficiales venizelistas organizaron un golpe militar, forzando la abdicación de Constantino en primer lugar, y después el procesamiento y ejecución de seis políticos y militares conservadores a los que se consideraba particularmente responsables del desastre de Asia Menor. Pero nada que tuviera alguna solidez vino a substituir a lo que había sido desbancado. A diferencia del golpe de Primo de Rivera en España del siguiente año, la junta militar no contaba con un solo dirigente fuerte, sino que formaba un grupo sin aspiraciones a gobernar por sí mismo. El hijo de Constantino, Jorge, pasó a ser nominalmente rey, pero no era sino una marioneta de los conjurados. Venizelos permaneció en el extranjero, receloso del extremismo de la junta y prefiriendo emplear su prestigio internacional para negociar el nuevo tratado de paz con Turquía, especialmente aquellas partes que regulaban la expulsión de los griegos de Asia Menor. Ninguno de los políticos dispuestos a colaborar con la junta logró establecer su autoridad. El caos era económico tanto como político: hacia comienzos de 1924 el coste de la vida se había triplicado desde 1921 y el valor del dracma se había depreciado en tres cuartas partes. En agosto de 1923 surgió un peligro nuevo cuando el régimen de reciente creación de Mussolini ocupó Corfú durante tres meses. Creyendo que era posible aprovechar el desorden reinante en Grecia, ciertos oficiales derechistas intentaron derrocar a la junta en octubre; su fracaso no hizo sino acelerar las purgas que se habían iniciado en 1922 de figuras de derechas de la vida pública, y aumentar el poder de los extremistas politicos y militares.

A las restantes dolencias de Grecia vino entonces a sumarse una feroz lucha faccional entre fuerzas liberales y radicales. Al lograr sus partidarios una gran victoria en las elecciones de diciembre de 1923, Venizelos regresó del exterior, creyendo que podría solventar la crisis constitucional del mismo modo que lo había hecho en 1910. Pero la junta no quiso aceptar su plan de una monarquía constitucional limitada, y tampoco lo aceptaron los políticos republicanos, pese a los malos resultados obtenidos en las elecciones. Venizelos renunció pasado un mes, y volvió a su exilio voluntario. En abril de 1924 se proclamó una república, pero fue un 
régimen lamentable, con poco respaldo público, que hubo de enfrentarse a enormes problemas que exigían una solución urgente, sin figuras fuertes en la dirección, a menudo sujeta a los caprichos de los jefes militares.

El idealismo que redimió a la Segunda República española, pese a sus muchos problemas, encontró escasa expresión en Grecia. En sus primeros años, el nuevo régimen recordaba más a la república portuguesa de 1910 - frágil, invertebrada, falta de ideales-. Ello se advierte en la continua crisis económica que acosó a Grecia a mediados de los años veinte, una edad dorada en la mayoría de los países capitalistas. Se advierte también en su historial político: cinco gobiernos se sucedieron entre sí en 1924, y en 1925 uno de los generales, Pangalos, llevó a cabo un golpe "en defensa de la república». A los pocos meses se había convertido en dictador, a su vez derrocado por Kondylis, otro general que contribuiría al surrealismo de la historia griega de entreguerras con la restauración, en agosto de 1926, de aquella república a cuya caída él mismo contribuiría nueve años después.

Y pese a todo, en parte como reacción a las múltiples humillaciones y al caos de este primer período, la situación empezó a mejorar lentamente. Durante casi dos años, Alexandros Zaimes, un moderado ya entrado en años, dirigió unos gobiernos de reconciliación cuya finalidad era apaciguar las pasiones y restaurar el consenso. Se consiguió controlar la inflación, los generales fueron retirándose gradualmente de la política. Al decrecer el grado de turbulencia, Venizelos regresó del extranjero y ganó abrumadoramente las elecciones de agosto de 1928. Había comenzado su tercer y último período en el poder. El gobierno de Venizelos de 1928 a 1932, aunque mucho menos espectacular que los precedentes, consiguió logros considerables. Participó activamente en cuestiones diplomáticas, conciliando diferencias con Italia y Yugoslavia y estableciendo buenas relaciones hasta con Turquía. También se distinguió su régimen en las reformas interiores. Se completó el proceso de reasentamiento de los refugiados, se llevaron a cabo importantes programas de obras públicas, se fomentó la industria y el comercio, se creó el crédito agrícola y servicios técnicos rurales, se amplió la enseñanza primaria considerablemente y se llevaron a cabo otras fundamentales reformas educativas.

Pero Grecia no iba a escapar tan fácilmente a sus antiguos demonios de conflictos y desórdenes. Cuando la depresión económica mundial empezó a afectar al país en 1930 y 1931, la economía volvió a iniciar su deterioro. El sensato intento de Venizelos de recobrar las buenas relaciones con Turquía en 1930 supuso el inicio de una erosión en la adhesión a su persona entre los refugiados, hasta el momento sus más enérgicos defensores. Y Venizelos no era tampoco el hombre que había sido en su 
día. Más inseguro y más revanchista que antes, menos sensible políticamente, más indeciso, consiguió enajenarse las simpatías de sus antiguos lugartenientes mientras ofendía a los monárquicos simultáneamente. Venizelos siguió siendo liberal, pero ni tan socialmente comprometido ni tan idealista como había sido anteriormente. Ello se hizo patente en la represiva legislación que aprobó en 1929 contra el nuevo partido comunista, poniendo gravemente en peligro las libertades civiles y concediendo poderes excesivos a la policía. Es también evidente en la perniciosa costumbre consolidada por él - costumbre que aún hoy acosa a Grecia-de alterar el sistema electoral con cada nueva elección, para dar a sus partidarios la máxima ventaja.

No obstante la manipulación electoral, en los comicios de septiembre de 1932 la situación de los venizelitas estaba lo bastante quebrantada para que perdieran la mayoría parlamentaria. Pero dado que tampoco el partido populista de la oposición consiguió la mayoría, los venizelistas volvieron al poder y convocaron nuevas elecciones para marzo de 1933. Esta vez - a pesar de que habían alterado de nuevo el sistema electoralsu derrota fue clara, y los populistas dirigidos por Tsaldares obtuvieron una victoria sólida. Venizelos pareció dispuesto a aceptar los resultados, pero no así algunos de los generales que habían intervenido políticamente en los pirmeros años de la república. Como la CEDA en España, los populistas eran antiguns monárquicos que sólo en tiempos recientes y bajo fuertes presiones habian aceptado al fin la república. Ello no constituía garantía suficiente para los oficiales republicanos dirigidos por el impetuoso general Plastiras, a cuyo parecer, si se les permitía subir al poder, los populares restaurarian la monarquía.

El pronunciamiento de Plastiras cuando los resultados electorales estaban anunciándose fue un fracaso ridículo; completamente espontáneo y sin preparación, fue aplastado en un día. Pero bastó para desatar un pernicioso ciclo de acontecimientos que, tres años después, produciría la primera dictadura duradera de la historia griega contemporánea. Como en 1915-17 (que trajo consigo el Cisma), 1944-46 (que llevó a la Guerra Civil griega) y 1965-67 (que desembocó en la Junta), en 1933-36 Grecia parecía atrapada en un torbellino que la llevaba inexorablemente a la ruina. El recurso a la ilegalidad de Plastiras proporcionó justificación moral a los extremistas de la oposición y les revitalizó psicológicamente. Ello generó en primer lugar un intento de implicar a Venizelos en el conato de golpe, y después, el 6 de junio de 1933, a un intento de asesinarlo. Pese a que las pruebas involucraban a la policía de Atenas en este delito, el nuevo gobierno de Tsaldares no insistió en seguir adelante con la investigación. Cuando, pasado un año, fue detenido al fin un responsable, su juicio fue aplazándose hasta que vino la dictadura, y entonces se aban- 
donó por completo. Entre tanto, las purgas de funcionarios vinculados a Venizelos en el ejército y la administración continuaban con rapidez, si bien no con la intensidad de los períodos de 1915-17 ó 1920-22, porque los venizelistas seguían controlando el Senado y porque había un sector de los populistas que aún deseaban la reconciliación. No obstante, incluso en esta etapa, que se puede comparar a la fase inicial del llamado «bienio negro" español (de noviembre de 1933 a octubre de 1934), la política griega dio un viraje a la derecha bastante más acusado que el ocurrido en España.

La segunda etapa en el descenso hacia la dictadura fue precipitada en marzo de 1935, una vez más por la ineptitud de las facciones militares venizelistas. Aunque Plastiras se había preparado mejor esta vez y el propio Venizelos había prestado su apoyo de mala gana, la insurrección fue sofocada sin gran dificultad. Como en la España de octubre de 1934, la revolución estalló con fuerza sólo en algunas regiones - Macedonia y Creta- mientras el resto del país seguía pasivo. Derrotados, Venizelos y la mayor parte de los oficiales rebeldes huyeron al exilio. Tsaldares actuó con presteza para abolir el Senado en primer lugar y eliminar a los venizelistas de todos los puestos de influencia que aún ocuparan, y después para convocar elecciones en junio, boicoteadas por los partidos republicanos. Pero ni siquiera esto bastó para pacificar a los extremistas monárquicos, dirigidos por Kondylis, el antiguo general radical que había derribado a Pangalos en 1926 para restaurar la república democrática, impulsado por ideas simplistas y ambiciones personales. Kondylis forzó la salida del poder de Tsaldares en octubre y creó un régimen de excepción. Además de endurecer mucho la represión, hizo que los pocos diputados que asistieron a una sesión parlamentaria esquelética declararan la restauración de la monarquía, y después llevó a cabo una farsa de plebiscito que, con una supuesta ventaja del $97 \%$ frente al $3 \%$, invitó al hijo de Constantino, Jorge II, a volver del exilio.

Habiendo ya actuado como rey en la sombra a merced de los militares en 1922-23, Jorge II pareció al principio partidario de una estrecha legalidad constitucional. Se apresuró a deshacerse de su benefactor, Kondylis; después inició una política conciliatoria hacia los venizelistas y convocó nuevas elecciones (las cuartas en cuatro años) para enero de 1936. Los resultados de éstas, llevadas a cabo limpiamente bajo un sistema de representación proporcional, confirmaron que Grecia estaba dividida por igual entre monárquicos y venizelistas, hasta tal punto que el pequeño partido comunista, con un cinco por ciento de escaños, tenía en sus manos el equilibrio de poder entre ambos. Habiendo padecido ambos partidos recientemente la impetuosidad de los generales adeptos a ellos, y siendo el rey al parecer sincero en sus esfuerzos por terminar de una vez 
por todas con las consecuencias del cisma, parecía posible una solución pacífica a la crisis.

Pero el antiguo antagonismo entre los dos grandes partidos políticos hizo fracasar varios esfuerzos para formar una amplia coalición entre sí, y movió a ambos grupos a llevar a cabo negociaciones (secretas, para evitar contrariar al ejército) con los comunistas para que éstos respaldaran gobiernos dominados por ellos. Los comunistas, confiando imprudentemente en lo que juzgaron un poder nuevo para ellos, contribuyeron a su vez a la crisis, primero debilitando a los grandes partidos revelando las negociaciones que se habian realizado con uno y otro, y después lanzando la mayor ola de huelgas de la historia griega. El último ingrediente de lo ocurrido fue en parte accidental: los políticos populistas en que podía confiar el rey. Tsaldares y Demertzis murieron en los primeros meses de 1936 (al igual que Venizelos y Kondylis), con la consecuencia de que Jorge II recurrió a Metaxas para ser primer ministro.

Metaxas era el jefe del Estado Mayor que en 1915 se había manifestado contrario a la intervención en la I Guerra Mundial, pero que había dejado el ejército y entrado en política en los años veinte. Pese a sus constantes fracasos en crear un gran partido conservador independiente de los populistas, gozaba de considerable prestigio entre la derecha como líder competente. Fue algo que Metaxas supo demostrar después de ser nombrado primer ministro el 1 de abril, al manipular los hechos - la ola de huelgas, las negociaciones entre los comunistas y los dos partidos tradicionales, y la agitación que ambas cosas generaban en aquel Ejército tremendamente conservador salido de las purgas que siguieron al fracaso de los golpes de Plastiras- para convencer al rey de que respaldara la proclamación de una dictadura el 4 de agosto.

Así pues, sin la ayuda de un partido de masas, ni apoyo específico en el Ejército, sin emplear ni la violencia ni la amenaza de violencia, Metaxas creó una dictadura que perduraría hasta la II Guerra Mundial. Pese a que hizo uso de una parte del ritual y el lenguaje ideológico del fascismo para consolidar su dictadura, su singularidad se hace patente en el modo nada fascista en que subió al poder y en que concluyó su dictadura (por la derrota bélica ante Hitler). Todo había dependido del rey. No está claro el motivo por el que Jorge It, en un principio aparentemente convencido de que la reconciliación era necesaria para la supervivencia a la larga de su dinastía, cambió de rumbo tan drásticamente. No era un hombre particularmente inteligente o valeroso, como los hechos posteriores pondrían de manifiesto. Pero cuesta creer que el estallido de la Guerra Civil española - sólo dos semanas antes de tomar su decisiónno influyera en él. La situación se había deteriorado en España hasta el 
punto de llegar a un conflicto fraticida y lo mismo podría ocurrir en Grecia. Con una historia pasada tan turbulenta, no era probable que los dos grandes partidos griegos pudieran colaborar eficazmente, por prometedores que fueran los indicios por el momento. Y la agitación social suscitada, aunque insignificante con criterios europeos, era aterradora en un país no habituado a los conflictos de clase. Más prudente sería seguir la vía segura de una dictadura moderada, encabezada por un hombre inteligente y capacitado.

Así pues, no obstante las muchas diferencias existentes entre Grecia y los demás países de la Europa meridional, expuestas al comienzo de este trabajo, su historia acabó por mostrar muchas semejanzas con la de éstos. Los paralelismos con España son especialmente llamativos. Aunque no supuso una parte tan importante de la historia griega del siglo xIx, la polarización ideológica entre monárquicos y republicanos llegó a ser tan enconada - y en ocasiones aún más - de lo que fue en España. Una similar transformación se operó en relación a la intervención militar en política. A partir de 1922 el Ejército actuó con tanta frecuencia en la política griega porque, como el ejército español de comienzos del siglo XIX, no tenía una única orientación ideológica, sino que intervenía a favor tanto del liberalismo como del conservadurismo. Otra trágica semejanza con España fue que, en todos los ámbitos, el peso de anteriores conflictos inmovilizó constantemente a los moderados que quisieron forjar la reconciliación, haciendo que sus esfuerzos fueran tímidos y de duración breve. También hizo que los partidarios de los grandes bloques políticos no pudieran aceptar la legitimidad de sus contrincantes y explica la facilidad con que tuvieron acceso a métodos ilegales o semi-legales para impedir su subida al poder.

Los paralelismos cronológicos son también notables, salvo en la década de 1910. Comienzan con las humillaciones sufridas por Grecia y España en las guerras turca y de Cuba de 1897 y 1898 respectivamente, y continúan con el anhelo de regeneración que caracterizó el decenio siguiente y produjo acontecimientos decisivos - aunque de índole muy distinta - en ambos países en 1909. Las coincidencias se reanudan en 1922: la derrota griega en Asia Menor es en cierto modo una versión enormemente agrandada de la derrota española en Annual y en ambos paises ocurrieron importantes cambios de régimen en 1923 y 1924. Las cronologías coinciden sobre todo en la década de 1930, primero porque las fuerzas de la izquierda iniciaron el recurso a la violencia en 1933 y 1934 (el golpe de Plastiras y la revolución de octubre en Cataluña y Asturias respectivamente), que a su vez generó un inmediato contraataque de la derecha y después una profunda polarización política que, en el 
verano de 1936, desembocaría en la Guerra Civil española y, dos semanas después, en la dictadura griega.

Algunas de las figuras y de los acontecimientos también se parecen entre sí. Azaña y Venizelos fueron realmente grandes hombres de Estado pero también con grandes defectos, especialmente por la arrogancia que ambos desarrollaron una vez en el poder, arrogancia que contribuye a explicar los encendidos odios que despertaban entre sus enemigos. El "accidentalismo" de Tsaldares y la manera en que tanto él como su Partido Popular fueron superados por extremistas de la derecha, nos hace pensar en Gil Robles y la CEDA. Kondylis, el exaltado irresponsable que pasó de un fuerte republicanismo al autoritarismo, recuerda en personalidad y en trayectoria política a Queipo de Llano. Por último, los puntos fuertes y débiles de Alfonso XIII se nos hacen algo más comprensibles si lo comparamos con Constantino y Jorge II. Aunque era un hombre altivo y rebasó con frecuencia su mandato constitucional, Alfonso XIII fue mucho menos lejos en ambos aspectos que Constantino, un rey tosco, con inclinaciones autoritarias, el cual perjudicó seriamente a Grecia con su extrema y partidista ingerencia en la vida política. Y si bien Alfonso XIII traicionó su compromiso constitucional al aceptar la dictadura de Primo de Rivera, había sido objeto de provocaciones considerablemente mayores que Jorge II en Grecia cuando recurrió a Metaxas en 1936.

El valor de una perspectiva comparativa en cualquier estudio sobre historia española es que nos permite una mejor comprensión de esa historia. En un contexto más amplio, lo que parecen ser defectos exclusivamente españoles resultan ser característicos también de otros países, y se hace patente que los problemas de España tienen su equivalente en otros lugares. Es claro que no se puede esperar una perfecta correspondencia entre la historia de dos países. Grecia y España fueron muy diferentes, debido en gran parte a que - con todas las transformaciones experimentadas por Grecia en las décadas de 1910 y 1920- España siguió siendo un país más polifacético, ya fuera socialmente, políticamente o en su diversidad regional. Sobre todo, la lucha social en España fue mucho más intensa que en Grecia, por lo cual la "guerra civil fría" que vivió ésta a partir de 1915 no llegó en 1936 a convertirse en guerra civil abierta y sin límites, como en aquélla. Pero, no obstante todas las diferencias, el descubrimiento incluso de unas pocas pautas y problemas comunes contribuye a romper la tendencia a estudiar los países como si existieran en células herméticas y constituye en sí mismo un paso importante hacia una mejor comprensión del pasado. 